I. Truyen - P. De Pauw $\cdot$ P. N. Jørgensen •

C. Van Schravendijk · O. Ubani - K. Decochez •

E. Vandemeulebroucke $\cdot$ I. Weets $\cdot$ R. Mao $\cdot$

D. G. Pipeleers · F. K. Gorus • The Belgian

Diabetes Registry

\title{
Proinsulin levels and the proinsulin:C-peptide ratio complement autoantibody measurement for predicting type 1 diabetes
}

Received: 9 March 2005 / Accepted: 4 July 2005 / Published online: 7 October 2005

(C) Springer-Verlag 2005

\begin{abstract}
Aims/hypothesis: We investigated whether random proinsulin levels and proinsulin:C-peptide ratio (PI:C) complement immune and genetic markers for identifying relatives at high risk of type 1 diabetes. Materials and methods: During an initial sampling, random glycaemia, proinsulin, PI:C and HLA DQ genotype were determined in 561 non-diabetic first-degree relatives who had been positive for islet autoantibodies on one or more occasions and in 561 age- and sex-matched persistently antibodynegative relatives. Results: During follow-up (median 62 months), 46 relatives with antibodies at entry developed type 1 diabetes. At baseline, antibody-positive relatives $(n=338)$ had higher PI:C values $(p<0.001)$ than antibodynegative subjects with $(n=223)$ or subjects without $(n=561)$ later seroconversion. Proinsulin and PI:C were graded according to risk of diabetes as expressed by positivity for (multiple) antibodies or IA-2 antibodies, especially in persons carrying the high-risk $H L A D Q 2 / D Q 8$ genotype and in prediabetic relatives. In the presence of multiple or IA-2 antibodies, a PI:C ratio exceeding percentile 66 of all antibody-negative relatives at entry $(n=784)$ conferred a 5year diabetes risk of $50 \%$ and $68 \%$, respectively $(p<0.001$ vs $13 \%$ for same antibody status with PI:C $<$ percentile 66 ). Cox regression analysis confirmed random PI:C as an independent predictor of the risk of diabetes $(p \leq 0.001)$. Conclusions/interpretation: Random proinsulin and PI:C represent dynamic markers of the state of beta cell function that complement immune markers in identifying relatives who are at homogeneously high risk of contracting
\end{abstract}

\footnotetext{
I. Truyen - P. De Pauw - C. Van Schravendijk - O. Ubani · K. Decochez - E. Vandemeulebroucke - I. Weets - R. Mao · D. G. Pipeleers · F. K. Gorus $(\bowtie)$

Diabetes Research Center, Brussels Free University-VUB,

Laarbeeklaan 103,

1090 Brussels, Belgium

e-mail: frans.gorus@az.vub.ac.be

Tel.: +32-2-4775030

Fax: $+32-2-4775047$

P. N. Jørgensen

Novo Nordisk,

Copenhagen, Denmark
}

type 1 diabetes and are therefore eligible for secondary prevention trials.

Keywords C-peptide $\cdot H L A D Q \cdot$ IA-2 antibodies · Islet antibodies · Prediction · Proinsulin - Type 1 diabetes

Abbreviations GADA: antibodies to $\mathrm{M}_{\mathrm{r}} 65,000$ glutamic acid decarboxylase - IA-2A: antibodies to insulinomaassociated protein-2 - IAA: insulin autoantibodies - ICA: islet cell cytoplasmic antibodies - P66: 66th percentile PI:C: proinsulin:C-peptide ratio - TRFIA: time-resolved fluorescence immunoassay

\section{Introduction}

To identify persons at risk of diabetes among first-degree relatives of type 1 diabetic patients we currently use detection of islet cell cytoplasmic antibodies (ICA), insulin autoantibodies (IAA), antibodies to the $\mathrm{M}_{\mathrm{r}} 65,000$ isoform of glutamic acid decarboxylase (GADA) and/or antibodies to the intracellular domain of insulinoma-associated protein-2 (IA-2A) [1-6]. Relatives thus identified can then be enrolled in prevention trials aimed at preserving the residual beta cell mass by stopping or delaying the pathogenic process [7-9]. However, the rate of beta cell destruction among antibody-positive relatives varies considerably and some do not develop hyperglycaemia for many years [1-9]. In first-degree relatives of type 1 diabetic patients the presence of multiple autoantibodies or of IA-2A — even on one occasion - is associated with a high 5 -year risk of diabetes, which may reach $80 \%$ in carriers of HLA DQA1*0301-DQB1*0302 (DQ8)/DQA1*0501$D Q B 1 * 0201(D Q 2)[5,10,11]$. However, the predictive value of these marker combinations goes at the expense of diagnostic sensitivity, as they detect only about $30 \%$ of prediabetic relatives $[10,11]$. There is therefore a need for additional biological markers capable of identifying more prediabetic relatives.

Measuring early hormonal markers may further improve risk assessment in relatives [12-21]. Loss of (first-phase) 
insulin response - during an intravenous glucose tolerance test - is considered highly predictive of impending diabetes in antibody-positive first-degree relatives [15-19] and has been used as an inclusion criterion in some diabetes prevention trials $[9,19]$. However, this test is not optimally reproducible and is difficult to carry out on a large scale in non-diabetic risk groups comprising children, students and active young adults [20].

Elevated fasting proinsulin levels and proinsulin:C-peptide (PI:C) ratios have been described in recent-onset type 1 diabetic patients [21] and in prediabetic antibody-positive siblings with low first-phase insulin responses [12]. We investigated whether measurement of proinsulin and the PI:C ratio in random blood samples could improve the predictive value of immune and genetic markers in identifying persons at risk of developing type 1 diabetes. The long-term goal is to facilitate identification of those firstdegree relatives of type 1 diabetic patients with a homogeneously high 5-year risk of diabetes, with a view to including them in secondary prevention trials designed to lead to conclusions within that time-frame.

\section{Subjects and methods}

Subjects and data collection Siblings $(n=1,899)$, offspring $(n=2,806)$ and parents $(n=792)$ of type 1 diabetic patients were consecutively recruited by the Belgian Diabetes Registry between 1 January 1989 and 27 November 2002 according to previously defined criteria $[10,11,22]$. This group of first-degree relatives $(n=5,497)$, aged between 0 and 39 years, was followed for a median (interquartile period) of 52 (43-59) months. The relatives were not preselected on the basis, for example, of ICA-positivity or known prediabetic state. Their probands are considered representative of the whole Belgian population of type 1 diabetic patients [23]. After obtaining written informed consent from each subject or the subject's parents, we asked them to complete a short questionnaire with demographic, familial and personal information. Blood was sampled randomly at inclusion and (as a rule) at yearly intervals during follow-up.

Relatives who developed diabetes during follow-up were identified through repeated contacts with Belgian endocrinologists and paediatricians, self-reporting through yearly questionnaires and through a link with the Belgian Diabetes Registry patient data base, where newly diagnosed diabetic patients who are younger than 40 years and reside in Belgium are registered. The study was conducted in accordance with the guidelines in The Declaration of Helsinki as revised in 2000 (http://www.wma.net/e/policy/ b3.htm) and approved by the ethics committees of the Belgian Diabetes Registry and the participating university hospitals.

Serum, plasma and whole-blood samples were divided in aliquots and stored at $-80^{\circ} \mathrm{C}$ until analysed for glucose, $\mathrm{HbA}_{1} \mathrm{c}$ and diabetes-associated autoantibodies. Autoantibody-positive relatives were genotyped for $H L A D Q$. Random proinsulin, C-peptide and PI:C ratio were determined in the initial sample of relatives who developed autoantibodies on at least one occasion during the observation period (561 out of the 5,497 relatives) and in the initial sample of 561 individually age- and sex-matched relatives who remained antibody-negative throughout follow-up. The median (interquartile range) follow-up time of these 1122 relatives was $62(50-69)$ months. Of the 338 relatives who were antibody-positive at first sampling, 194 (57\%) were confirmed as antibody-positive at $\geq 1$ later time-point. To assess whether elevated PI:C values persisted in these 338 antibody-positive relatives, $\mathrm{PI}: \mathrm{C}$ was determined in the follow-up sample after 1 year when available $(n=284)$. For prediabetic relatives all available samples up to clinical diagnosis were analysed.

Analytical methods ICA were determined by indirect immunofluorescence, IA-2A, GADA and IAA by liquidphase radiobinding assays, and $H L A D Q$ polymorphisms by allele-specific oligonucleotide genotyping as previously described [24-26]. Plasma glucose was measured on $\mathrm{NaF}$ plasma as before [10]. $\mathrm{HbA}_{1} \mathrm{c}$ levels were determined by immunoassay (Roche, Basel, Switzerland) on a Cobas Integra 400 analyzer (Roche). Proinsulin and C-peptide were determined in plasma collected in K-EDTA monovettes (Sarstedt, Darmstadt, Germany) supplemented with aprotinin (Trasylol; Bayer, Brussels, Belgium; final concentration 600 kallikrein inactivator units $/ \mathrm{ml}$ ). Plasma proinsulin was measured by ELISA [27]. The lower and upper level of quantification amounted to 0.9 and $300 \mathrm{pmol} / 1$, respectively. Up to a 500 -fold excess of C-peptide did not interfere in the proinsulin assay. Because of high crossreactivity with conversion intermediates $[74 \%$ for split (32-33) proinsulin, 65\% for des(31,32) proinsulin, $78 \%$ for split $(65-66)$ proinsulin and $99 \%$ for $\operatorname{des}(64,65)$ proinsulin], the assay was considered to measure total proinsulin immunoreactive material [27]. It comprises two separate overnight incubations allowing the monoclonal antibodies used in the assay to compete with IAA (if present in the plasma tested) for binding to proinsulin. In these conditions IAA may only cause an underestimation of total proinsulin concentration at very high IAA levels ( $>4 \%$ tracer binding; P. De Pauw, personal communication). Such high IAA values were observed in less than 5\% of the prediabetic and non-diabetic relatives at first sampling in the present study. The proinsulin ELISA can thus be considered to measure the sum of free and IAA-bound proinsulin. Total plasma C-peptide levels were determined by a two-step time-resolved fluorescence immunoassay (TRFIA) using a commercial kit (AutoDelfia-C-peptide kit B081-101; Perkin-Elmer, Wallac Oy, Turku, Finland) with in-house modifications. Fetal bovine serum $(10 \%[\mathrm{v} / \mathrm{v}]$, Hyclone FBS; Perbio Science, Erembodegem, Belgium) was added to the incubation buffer to avoid heterophile antibody binding [28] and an additional washing step, preceding the incubation with the labelled antibody, was carried out to eliminate interference by K-EDTA from the samples. The assay measures the total C-peptide level (i.e. true C-peptide and proinsulin including its split- and desforms) with a lower level of quantification at $30 \mathrm{pmol} / \mathrm{l}$ 
Table 1 Metabolic and hormonal characteristics at study entry in relatives classified according to their baseline antibody status

\begin{tabular}{lllr}
\hline Characteristic & Ab-positive $^{\mathrm{a}}$ & Ab-negative $^{\mathrm{b}}$ & \multicolumn{1}{l}{$p$} \\
\hline$n$ & 338 & 784 & \\
Age, years & $14(8-23)$ & $13(6-24)$ & 0.263 \\
Male/female, $n / n$ (ratio) & $168 / 170(0.99)$ & $378 / 406(0.93)$ & 0.647 \\
Siblings/offspring/ & $156 / 149 / 33$ & $293 / 411 / 80$ & 0.019 \\
parents $(n / n / n)$ & & & \\
Glucose (mmol/l) & $4.8(4.4-5.3)$ & $4.8(4.4-5.1)$ & 0.169 \\
Proinsulin (pmol/1) & $12.6(7.1-25.4)$ & $11.3(6.8-20.9)$ & 0.071 \\
C-peptide (pmol/1) & $698(438-1025)$ & $702(451-1070)$ & 0.475 \\
Proinsulin:C-peptide & $2.0(1.3-2.9)$ & $1.7(1.2-2.4)$ & $<0.001$ \\
ratio (\%) & & & \\
\hline
\end{tabular}

Data are $n ; n / n$ (ratio); $n / n / n$ or medians (interquartile range). Antibody-negative relatives who seroconverted to antibody positivity in follow-up samples $(n=223)$ and those who remained persistently antibody-negative $(n=561)$ did not differ in the parameters tested (not shown). The threshold for significance between Ab-positive and Ab-negative relatives was: $p<0.007$ (Bonferroni adjustment)

$A b$ antibody

${ }^{\text {a }}$ Positive for ICA, GADA, IA-2A, and/or IAA

${ }^{b}$ Negative for ICA, GADA, IA-2A and IAA

and was calibrated towards the international reference reagent for C-peptide (IRR C-peptide, code 84/510; NIBSC, South Mimms, UK). The level of true C-peptide was calculated by subtracting the proinsulin level measured by ELISA from the total C-peptide level measured by TRFIA and was used for further statistical analysis and for the exact calculation of the PI:C ratio using the formula: PI:C ratio $(\%)=100 \times$ proinsulin $(\mathrm{pmol} / \mathrm{l}$; ELISA)/[total C-peptide (pmol/l; TRFIA)-proinsulin (pmol/l; ELISA)].

Interassay coefficients of variation determined on human control sera amounted to 3\% $(n=40)$ for C-peptide and $8 \%$ $(n=84)$ for proinsulin at the level of $896 \mathrm{pmol} / \mathrm{l}(2.7 \mu \mathrm{g} / \mathrm{l})$ and $28 \mathrm{pmol} / \mathrm{l}(252 \mathrm{ng} / \mathrm{l})$, respectively.

Statistical analysis Statistical differences between groups were assessed by means of the Mann-Whitney $U$-test or by Kruskall-Wallis analysis for continuous variables and by the chi-square test, using Yates' correction or Fisher's exact test for categorical variables. Mc Nemar's test was used to compare sensitivities of different variables in the same cohort. In prediabetic subjects Spearman's rank correlation was used to investigate the relation between PI:C ratio and time to diabetes. Differences in diabetes-free survival were investigated by Kaplan-Meier analysis and log-rank test $[10,11]$. Cox proportional hazards model, performed by forward stepwise method, was used to investigate the independent contributions of risk factors identified by univariate analysis (whenever $p<0.1$ ), with $95 \%$ confidence intervals on hazard ratios [10,11]. All statistical tests were performed two-tailed by SPSS for Windows 11.0 (SPSS, Chicago, IL, USA) or by Epi Info Version 6 (USD, Stone Mountain, GA, USA) and considered significant whenever $p<0.05$ or, in case of $k$ comparisons, whenever $p<0.05 / k$ (Bonferroni adjustment) $[10,11]$.

\section{Results}

Changes in subject status During the study period, 50 of 5497 relatives $(0.9 \%)$ developed type 1 diabetes with a median (interquartile range) time to clinical onset of 33 (11-50) months. Of these, 46 (i.e. 92\%) were initially antibody-positive at entry (13\% progression to diabetes within 5 years; Kaplan-Meier analysis; not shown). The four others were antibody-negative at baseline but became antibody-positive at a later time $(0.5 \%$ progression to diabetes within 5 years; Kaplan-Meier analysis; not shown). None of the persistently antibody-negative relatives developed diabetes during follow-up.

Hormonal characteristics according to antibody status at first sampling Antibody-positive relatives had similar plasma glucose, C-peptide and proinsulin levels to antibodynegative relatives (Table 1), regardless of whether or not the latter seroconverted to antibody-positivity at a later time (not shown). However, antibody-positive relatives had higher

Table 2 Metabolic and hormonal characteristics at initial random sampling of relatives according to antibody status and development of type 1 diabetes during follow-up

\begin{tabular}{llllr}
\hline Characteristic & \multicolumn{2}{l}{ Ab-positive $^{\mathrm{a}}$} & Ab-negative $^{\mathrm{b}}$ & \multirow{2}{*}{ Overall $p$} \\
\cline { 2 - 3 } & Prediabetic & Non-diabetic & & \\
\hline$n$ & 46 & 292 & 784 & \\
Glucose (mmol/1) & $5.0(4.4-5.7)$ & $4.8(4.4-5.2)$ & $4.8(4.4-5.1)$ & 0.078 \\
Proinsulin (pmol/1) & $17.7(11.4-38.8)$ & $11.7(6.7-23.4)^{\mathrm{c}}$ & $11.3(6.8-20.9)^{\mathrm{d}}$ & 0.001 \\
C-peptide (pmol/1) & $642(410-1038)$ & $703(441-1026)$ & $702(451-1070)$ & 0.490 \\
Proinsulin:C-peptide ratio (\%) & $3.1(2.3-5.9)$ & $1.9(1.3-2.7)^{\mathrm{d}}$ & $1.7(1.2-2.4)^{\mathrm{d}}$ & $<0.001$ \\
\hline
\end{tabular}

Data are $n$ or medians (interquartile range). Threshold for overall significance: $p<0.012$ (Bonferroni adjustment). In case of significant overall $p$ value, the threshold for significance between individual groups is $p<0.017$ (Bonferroni adjustment) $A b$ antibody

${ }^{\text {a }}$ Positive for ICA, GADA, IA-2A, and/or IAA

${ }^{b}$ Negative for ICA, GADA, IA-2A and IAA

${ }^{c} p=0.002$ compared with initially antibody-positive prediabetic relatives

${ }^{d}<0.001$ compared with initially antibody-positive prediabetic relatives 


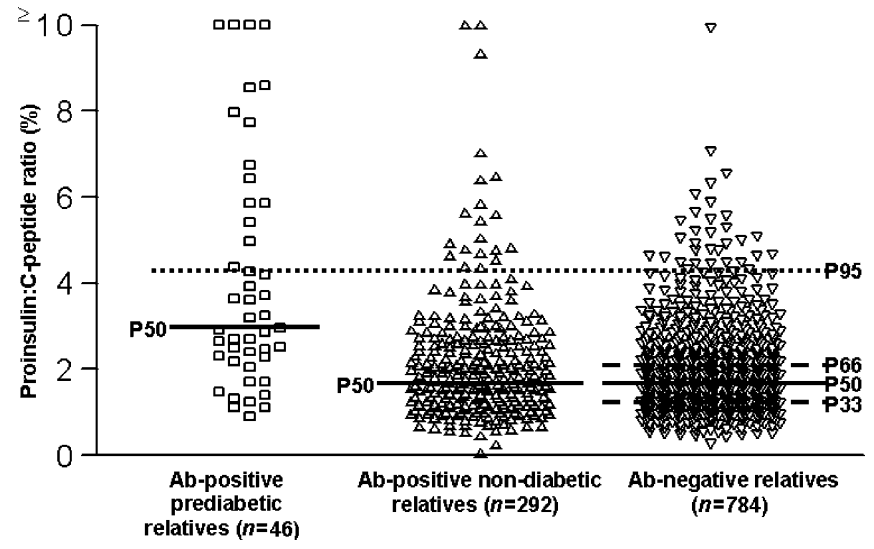

Fig. 1 Proinsulin:C-peptide (PI/C) ratio (\%) at initial sampling in antibody-positive prediabetic relatives $(n=46)$, antibody-positive non-diabetic relatives $(n=292)$ and antibody-negative relatives $(n=784)$. The dotted line at $4.1 \%$ indicates the cut-off value (percentile 95 in antibody-negative relatives) for increased PI:C ratio. Solid lines, median values (percentile 50 [P50]) of each group; interrupted lines, percentiles 33 (P33) and 66 (P66) of the control group

PI:C ratios $(p<0.001)$ than antibody-negative relatives (Table 1). The PI:C ratios of the latter were indistinguishable from values observed in 22 healthy control subjects from the general population (E. Vandemeulebroucke, personal communication). Whenever available (1,072 of 1 , 122 initial samples) $\mathrm{HbA}_{1} \mathrm{c}$ levels were within the normal range ( $<6 \%$; not shown).

PI:C ratio increased significantly according to the number of antibodies present (median [interquartile range] for $n=113$ with $\geq 2$ antibodies: $2.28[1.50-3.25] \% ; p<0.001$ vs 1.84 [1.19-2.69] $\%$ for $n=225$ with 1 antibody); a similar association of increased PI:C ratio with multiple antibodypositivity was found, when only molecular antibodies were considered (not shown). PI:C was also significantly higher in IA-2A-positive relatives ( $n=68 ; 2.45[1.60-3.94] \%)$ than in relatives with other antibody specificities (IAA, GADA or ICA) $(n=270 ; 1.88[1.25-2.71] \% ; p=0.001)$. When IA2A-positive and IA-2A-negative relatives were studied separately, PI:C ratio no longer increased with antibody number, but was only elevated (after stratification according to $H L A D Q$ status) in IA-2A-positive $D Q 2 / D Q 8$ heterozygotes $(n=20 ; 3.7[2.3-6.3]$; overall $p<0.001)$ (not shown).

Hormonal characteristics of prediabetic relatives at first sampling The subgroup of 46 prediabetic antibody-positive relatives had higher random proinsulin levels and PI:C ratios than non-diabetic antibody-positive relatives $(p \leq 0.002)$ or than antibody-negative $(p<0.001)$ relatives. However, the three groups did not differ in glycaemia (Table 2) or in glucose:C-peptide ratio (not shown). Initial PI:C values (Fig. 1) and proinsulin levels (not shown) of prediabetic subjects and non-diabetic relatives with or without autoantibodies showed a considerable overlap. Taking the 95th percentile of PI:C in antibody-negative relatives $(n=784)$ as cut-off ( $\geq 4.1 \%)$ (Fig. 1) an elevated ratio occurred in $37 \%$ of antibody-positive prediabetic relatives vs $7 \%$ of nondiabetic antibody-positive relatives and $5 \%$ of antibody-negative relatives ( $p<0.001$ vs prediabetic relatives) (Fig. 1).

Predictive value of high PI:C in antibody-positive relatives In 338 antibody-positive relatives at first sampling a PI:C ratio above the 66th percentile of antibody-negative relatives (P66; PI:C=0.021; Fig. 1) was associated with a $24 \%$ 5 -year risk of diabetes (36 diabetes events; $p<0.0001$ vs $4 \%$ in relatives with a PI:C ratio $\leq \mathrm{P} 66$ ) (Fig. 2(a)). In subjects with positivity for $\geq 2$ antibodies, progression to diabetes was significantly higher when the PI:C ratio was greater than P66 $(50 \%$; $p=0.0003$ vs $13 \%$ for PI:C ratio $\leq$ P66) (Fig. 2(b)). The screening sensitivity $[95 \% \mathrm{CI}]$ for combined presence of high PI:C ratio and multiple antibodies was $76 \%$ [62-90\%] (29 of 38 multiple antibodypositive diabetes cases predicted).

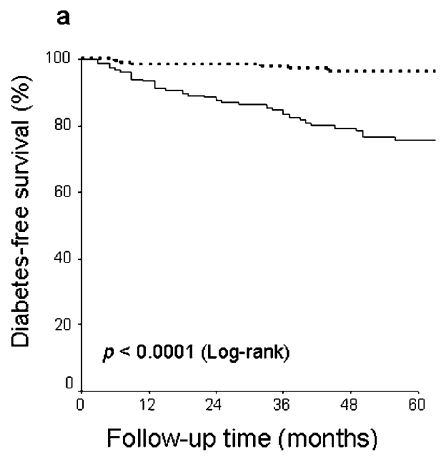

$\mathrm{PI} / \mathrm{C}$ ratio $\leq \mathrm{P} 66 \quad 183$

$\mathrm{PI} / \mathrm{C}$ ratio $>\mathrm{P} 66 \quad 155$

Fig. 2 Diabetes-free survival (\%) in all antibody-positive first-degree relatives at initial sampling $(n=338)(\mathbf{a})$, in multiple antibody-positive relatives ( $\geq 2$ antibodies among IAA, ICA, GADA and IA-2A; $n=113$ ) (b), and in IA-2A-positive relatives $(n=68)(\mathbf{c})$, stratified according to $\mathrm{PI}$ :C ratio ( $\leq \mathrm{P} 66$, dotted line vs $>\mathrm{P} 66$, unbroken line). Five-year
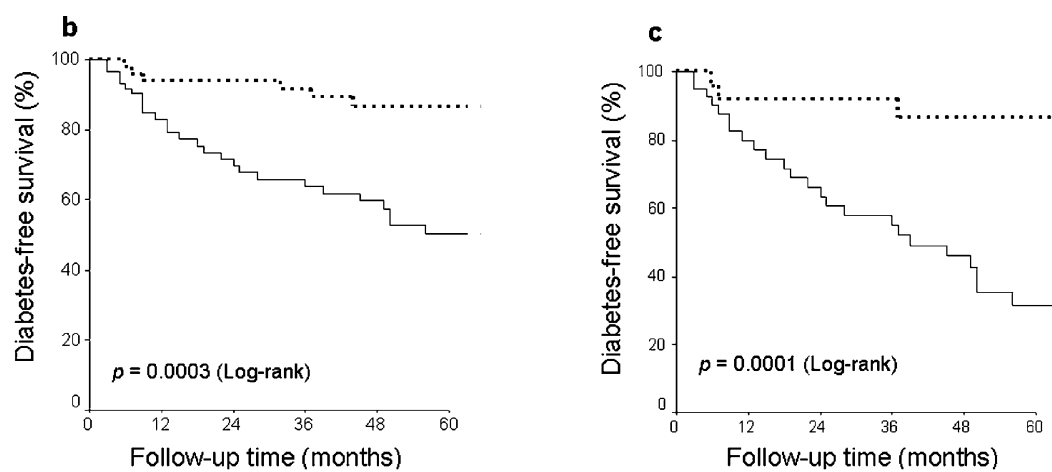

$\begin{array}{llll}41 & 38 & 31 & 26 \\ 37 & 32 & 26 & 17\end{array}$

$\mathrm{PI} / \mathrm{C}$ ratio $\leq \mathrm{P} 6626$

22

$9 \quad 17 \quad 14 \quad 11$ (CI 76-97) (b) 87\% (CI 72-100) (c); for PI:C ratio $>$ P66. 76\% (C 68-83) (a), 50\% (CI 36-64) (b), 32\% (CI 15-48) (c). Numbers of subjects still under follow-up in each category (at 12-month intervals) are indicated beneath the time scale 
Table 3 Cox regression analysis in 338 initially antibody-positive first-degree relatives

\begin{tabular}{|c|c|c|c|}
\hline \multirow[t]{2}{*}{ Variable } & \multirow{2}{*}{$\begin{array}{l}\begin{array}{l}\text { Univariate } \\
\text { analysis }\end{array} \\
p\end{array}$} & \multicolumn{2}{|c|}{$\begin{array}{l}\text { Multivariate analysis (forward } \\
\text { stepwise method) }\end{array}$} \\
\hline & & $p$ & $\begin{array}{l}\text { Hazard ratio for } \\
\text { diabetes }(95 \% \mathrm{CI})^{\mathrm{a}}\end{array}$ \\
\hline IAA & 0.716 & NT & NT \\
\hline ICA & $<0.001$ & NS & NS \\
\hline GADA & $<0.001$ & NS & NS \\
\hline IA-2A & $<0.001$ & $<0.001$ & $7.2(2.8-18.8)$ \\
\hline $\begin{array}{l}\text { Number of } \\
\text { autoantibodies }\end{array}$ & $<0.001$ & 0.030 & $1.5(1.0-2.2)$ \\
\hline $\begin{array}{l}H L A D Q 2 / D Q 8 \\
\text { genotype }\end{array}$ & $<0.001$ & NS & NS \\
\hline $\begin{array}{l}\text { HLA DQ8 } \\
\text { haplotype }\end{array}$ & 0.002 & NS & NS \\
\hline $\begin{array}{l}H L A D Q 2 \\
\text { haplotype }\end{array}$ & 0.052 & 0.021 & $2.1(1.1-4.0)$ \\
\hline Proinsulin & 0.005 & NS & NS \\
\hline C-peptide & 0.332 & NT & NT \\
\hline $\begin{array}{l}\text { Proinsulin: } \\
\text { C-peptide ratio }\end{array}$ & $<0.001$ & $<0.001$ & $1.2(1.1-1.3)$ \\
\hline Age & 0.106 & NT & NT \\
\hline Sex & 0.577 & NT & NT \\
\hline Sibling & 0.002 & NS & NS \\
\hline
\end{tabular}

Calculations were done with Cox regression models. All variables were considered at initial sampling

NT not tested

${ }^{a}$ Data are hazard ratios $(95 \% \mathrm{CI})$

In IA-2A-positive relatives, the presence of a high PI:C ratio was associated with $68 \%$ progression to diabetes within 5 years ( $p=0.0001$ vs $13 \%$ progression for PI:C ratio $\leq$ P66) (Fig. 2c). The screening sensitivity $[95 \% \mathrm{CI}]$ of this marker combination was $87 \%$ [75-99\%] (26 of the 30 IA-2A-positive prediabetes cases were predicted).

Cox regression analysis The above analysis was confirmed by multivariate forward stepwise Cox regression analysis in the 338 antibody-positive relatives (Table 3). IA-2A was selected first as predictor of diabetes risk $(p<0.001)$. The PI:C ratio was selected in the next step $(p<0.001)$, followed by the presence of the HLA DQ2 risk haplotype and the number of autoantibodies $(p=0.021$ and $p=0.030$, respectively). The other parameters (including the high-risk genotype $H L A D Q 2 / D Q 8$ ) were statistically not significant and therefore dropped from the final model (Table 3).

Changes of PI:C over time When baseline PI:C ratios of prediabetic relatives were plotted against time to clinical onset (Fig. 3a), an inverse correlation was found (Spearman $\left.r_{\mathrm{s}}=-0.44, p=0.002\right)$. Fig. $3 \mathrm{~b}$ shows that the individual PI:C ratios tended to increase closer to diagnosis. A high PI:C ratio $>$ P66 persisted 1 year later in 16 of 25 IA-2A-positive relatives $(64 \% ; 10$ of 14 [71\%] in prediabetic subjects) and in 55 of $88(63 \%)$ antibody-positive relatives lacking IA-2A.

\section{Discussion}

This study indicates that elevated levels of proinsulin immunoreactive material and an elevated PI:C ratio precede onset of hyperglycaemia in randomly sampled non-diabetic first-degree relatives of type 1 diabetic patients. Antibodynegative relatives had partly overlapping but significantly lower proinsulin and PI:C values. The increase in ratio was more prominent in prediabetic subjects sampled within 40 months prior to disease onset than in prediabetic subjects sampled 40-110 months before. This possibly reflects an increased beta cell demand in those who are at risk of rapidly developing the disease. This is in line with Røder and co-workers, who reported that first-degree relatives who had diminished first-phase insulin release and were studied 1-28 months prior to disease onset exhibited a higher PI:C ratio than those with normal first-phase insulin response and no disease onset within this period [12].

To date we have found no difference in proinsulin and PI:C between antibody-negative relatives and a limited number of control subjects from the general population. This is at variance with a number of previous studies describing raised fasting proinsulin levels $[14,29,30]$ and PI:insulin ratios [14], independent of antibodies and $H L A$ $D Q$ status, in subjects at familial risk of type 1 diabetes. However, no such elevated values were observed in cord blood from newborn siblings of diabetic children [31]. These findings were interpreted as evidence of beta cell
Fig. 3 PI:C ratio (\%) according to time before clinical onset of type 1 diabetes. a At entry in 46 antibody-positive prediabetic first-degree relatives (nonparametric Spearman correlation coefficient: $r_{\mathrm{s}}=-0.44, p=0.002$ ). b Evolution in all antibodypositive prediabetic relatives with $\geq 2$ samples before diagnosis $(n=32)$
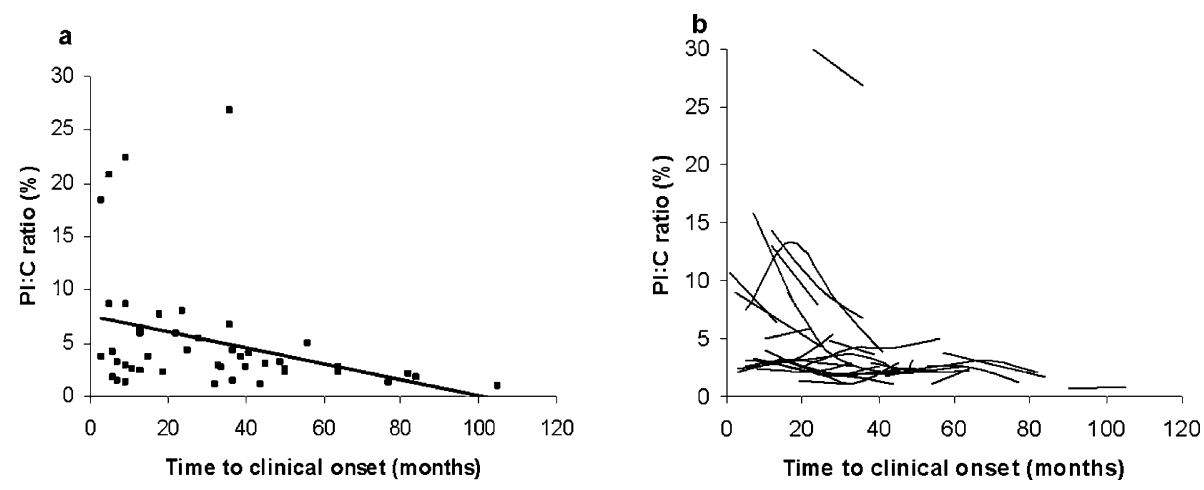
dysfunction occurring after birth but not leading to type 1 diabetes. The discrepancy with the present observation may relate to the use of random vs fasting values, different hormone and antibody assays, and low numbers both in older studies and our control group. However, it does not invalidate our observation of a(n) (further) increase in proinsulin and PI:C closer to diagnosis, which was also noted by others $[14,32,33]$. In particular, the use of random hormone levels may lead to more overlapping results between groups tested, but remains the only option to screen large groups of active non-diabetic relatives nationwide. Moreover, glucose stimulation was not found to vastly increase PI:C in healthy subjects [34].

It is conceivable that the elevated proinsulin levels and PI:C ratios measured at normal random glycaemia levels during the prediabetic period indicate an adaptation of the beta cell mass to maintain metabolic control in the face of increasing demands. In vitro studies on human beta cells isolated from normal donors have shown that a sustained activation of the cells by hyperglycaemia results in higher rates of proinsulin release and a higher PI:insulin ratio in the medium $[35,36]$. A similar beta cell activation increasing glucose sensitivity and proinsulin release may occur when a reduced islet mass has to secure glucose homeostasis. It is so far unknown whether such an activated state of the beta cells can accelerate their functional failure and/or shorten their life span. Alternatively, an elevated ratio in the medium may also result from cytokine influences on beta cells shown by in vitro experiments [37]; if so, this could then reflect an altered phenotype of a subpopulation of cells with reduced insulin-producing activities [37, 38], whereby the other beta cells maintain metabolic control. Finally, increased proinsulin and PI:C may relate to insulin resistance, identified as a risk factor for progression to diabetes [39].

At present there is no evidence that differences in proinsulin and PI:C ratio are caused by differences in hormonal clearance or by variations in autoantibody levels against insulin and/or proinsulin [12]. IAA have been detected in prediabetes and are known to contribute to a circulating pool of antibody-bound proinsulin, thereby increasing its half-life and its plasma concentration [40]. In our study this also remains a possible, but very unlikely explanation, since antibody-positive prediabetic and nondiabetic relatives did not differ in terms of prevalence or levels of IAA at first sampling and hormonal differences persisted between prediabetic and non-diabetic relatives after exclusion of IAA-positive subjects (not shown). Cox regression analysis also supported the notion that the PI:C ratio and IAA were independent of each other in diabetes prediction. Finally, proinsulin-specific autoantibodies are relatively infrequent [41].

Measurement of an increased PI:C ratio is in itself not a marker for progression to diabetes within 5 years, but serves this function when combined with a positive antibody assay in the sample. Antibody-positivity in randomly sampled first-degree relatives predicted $13 \%$ risk for diabetes within 5 years versus $0.5 \%$ for antibody-negative samples. The hormonal changes were also more marked in the presence of $\geq 2$ (molecular) antibodies or IA-2A, which indicates their significance as markers for 5-year risk of diabetes. Both in multiple antibody-positive and in IA-2Apositive relatives, a high PI:C ratio (>P66 of antibodynegative non-diabetic relatives) identified a subpopulation at higher risk of rapid progression (50 and 68\% 5-year risk respectively), whereas both marker combinations have a similar screening sensitivity. Moreover, in IA-2A-positive relatives an elevated PI:C ratio ( $>$ P66) improved disease prediction to the same extent as did the presence of the $H L A$ $D Q 2 / D Q 8$ genotype (5-year risk of 68 and $76 \%$, respectively). However, the PI:C ratio had a significantly higher screening sensitivity (87\% [95\% CI 75-99\%] versus $47 \%$ [95\% CI 29-65\%] for presence of the DQ2/DQ8 genotype) $(p<0.001$; not shown).

Cox regression analysis in antibody-positive relatives confirmed the independent diabetes predictor capacity of the random PI:C ratio as a complement to IA-2A. In contrast with $H L A D Q$ genotyping, which is more useful for screening programmes during the early preclinical phase [3, 34, 42-44], hormonal markers may be better suited to select high-risk antibody-positive subjects for prevention trials studying the efficiency of a given intervention within a 5 -year time frame $[12,13,15]$. The two screening strategies may provide a different time-window for testing preventive interventions during the prediabetic period. Unlike genotyping, the random $\mathrm{PI}: \mathrm{C}$ ratio also provides a dynamic parameter, whose increase over time indicates impending clinical onset in prediabetic relatives and is more amenable to large-scale monitoring than fasting or glucose-stimulated hormone measurements (e.g. intravenous glucose tolerance test) [12-19]. However, follow-up data indicate that in subjects with a high PI:C ratio this finding is not always confirmed in subsequent samples; hence this marker may not consistently identify high-risk subjects, possibly due to its 'random' nature. Parallel implementation of more elaborate dynamic tests (e.g. glucose clamps) may further clarify the changes in beta cell function during this evolution [45].

In conclusion, measurement of $\mathrm{PI}: \mathrm{C}$ ratio in first-degree relatives of type 1 diabetic patients complements current diabetes risk assessment based on antibody assays. This marker for the functional state of beta cells provides a dynamic parameter for identifying relatives at risk of rapid progression to diabetes. An elevated PI:C ratio in IA-2Apositive relatives identifies a subpopulation with a $68 \%$ risk of developing the disease within 5 years.

Duality of interest

None declared 
Acknowledgements The present work was supported by the Belgian Fund for Scientific Research (FWO-Vlaanderen: research grants 7-0021-96, 3-0113-97, G-0319-01, and G-0517-04, research fellowship to K. Decochez, I. Truyen and I. Weets; French-speaking branch: research grants 3-4525-96 and 3-4531-97) and by the research council of Brussels Free University-VUB (research fellowship to E. Vandemeulebroucke). The Belgian Diabetes Registry is supported by the Belgian National Lottery, the Ministries of Public Health of the Flemish and French Communities of Belgium, Weightwatchers, Ortho Clinical Diagnostics, Novo Nordisk, Lifescan, Roche Diagnostics and Bayer. The expert technical assistance of co-workers at the central unit of the Belgian Diabetes Registry (A. Demarré, V. Baeten, V. Claessens, L. De Pree, N. Diependaele, S. Exterbille, P. Goubert, C. Groven, A. Ivens, D. Kesler, F. Lebleu, M. Lichtert, E. Quartier, G. Schoonjans, M. Van der Linden and S. Vanderstraeten) is gratefully acknowledged. We would also like to thank the following university teams of co-workers for their excellent assistance in collecting samples and organising the fieldwork: (1) Antwerp: J. Michiels, S. Schrans, J. Van Elven and J. Vertommen; (2) Brussels: N. Alaerts, M. Bodson, T. De Mesmaeker and T. Ghysels; (3) Ghent: N. Christophe, E. De Man, S. De Neve, A. Hutse, A. Rawoens; (4) Leuven: M. Carpentier, A. Ceusters, C. Lauwers, H. Morobé. We sincerely thank all members of the Belgian Diabetes Registry who contributed to the recruitment of relatives for the present study, but cannot be listed individually because of space limitations.

\section{References}

1. The Expert Committee on the Diagnosis and Classification of Diabetes Mellitus (1997) Report of the Expert Committee on the Diagnosis and Classification of Diabetes Mellitus. Diabetes Care 20:1183-1197

2. Notkins AL, Lernmark $\AA$ (2001) Autoimmune type 1 diabetes: resolved and unresolved issues. J Clin Invest 108:1247-1252

3. Bingley PJ, Bonifacio E, Gale EAM (1993) Can we really predict IDDM? Diabetes 42:213-220

4. Gorus FK, Goubert P, Semakula C et al (1997) IA-2Aautoantibodies complement GAD65-autoantibodies in newonset IDDM patients and help predict impending diabetes in their siblings. Diabetologia 40:95-99

5. Verge CF, Gianani R, Kawasaki E et al (1996) Prediction of type 1 diabetes in first-degree relatives using a combination of insulin, glutamic acid decarboxylase and ICA 512 bdc/IA-2 autoantibodies. Diabetes 41:926-933

6. Kulmala P, Savola K, Petersen JS et al (1996) Prediction of insulin-dependent diabetes mellitus in siblings of children with diabetes. A population-based study. J Clin Invest 101:327-336

7. Gorus FK, Pipeleers DG, the Belgian Diabetes Registry (2001) Prospects for predicting and stopping the development of type 1 diabetes. Best Pract Res Clin Endocrinol Metab 15:371-389

8. European Nicotinamide Diabetes Intervention Trial (ENDIT) Group (2004) European Nicotinamide Diabetes Intervention Trial (ENDIT): a randomised controlled trial of intervention before the onset of type 1 diabetes. Lancet 363:925-931

9. Diabetes Prevention Trial-Type 1 Study Group (2002) Effects of insulin in relatives of patients with type 1 diabetes mellitus. N Engl J Med 346:1685-1691

10. Decochez K, De Leeuw IH, Keymeulen B et al (2002) IA-2 autoantibodies predict impending Type É diabetes in siblings of patients. Diabetologia 45:1658-1666

11. Decochez K, Truyen I, Van der Auwera B et al (2005) Combined positivity for HLA DQ2/DQ8 and IA-2 antibodies defines population at high risk of developing Type 1 diabetes. Diabetologia 48:687-694
12. Røder ME, Knip M, Hartling SG, Karjalainen J, Åkerblom HK, Binder C, the Childhood Diabetes in Finland Study Group (1994) Disproportionately elevated proinsulin levels precede the onset of insulin-dependent diabetes mellitus in siblings with low first phase insulin responses. J Clin Endocrinol Metab 79: $1570-1575$

13. Røder ME, Porte DJ, Schwartz RS, Kahn SE (1998) Disproportionately elevated proinsulin levels reflect the degree of impaired B cell secretory capacity in patients with noninsulindependent diabetes mellitus. J Clin Endocrinol Metab 83:604608

14. Hartling SG, Lindgren F, Dahlqvist G, Persson B, Binder C (1989) Elevated proinsulin in healthy siblings of IDDM patients independent of HLA identity. Diabetes 38:1271-1274

15. Srikanta S, Ganda OP, Rabizadeh A, Soeldner JS, Eisenbarth GS (1985) First-degree relatives of patients with type 1 diabetes mellitus. Islet-cell antibodies and abnormal insulin secretion. N Engl J Med 313:461-464

16. Lo SSS, Hawa M, Beer SF, Pyke DA, Leslie RDG (1992) Altered islet beta-cell function before onset of type 1 (insulindependent) diabetes mellitus. Diabetologia 35:277-282

17. Robert JJ, Deschamps I, Chevenne D, Roger M, Mogenet A, Boitard C (1991) Relationship between first-phase insulin secretion and age, HLA, islet cell antibody status, and development of type 1 diabetes in 220 juvenile first-degree relatives of diabetic patients. Diabetes Care 14:718-723

18. Bingley PJ for the ICARUS Group (1996) Interactions of age, islet cell antibodies, insulin autoantibodies, and first-phase insulin response in predicting risk of progression to IDDM in $\mathrm{ICA}^{+}$relatives. The ICARUS Data Set. Diabetes 45:1720-1728

19. Bingley PJ, Colman P, Eisenbarth GS et al (1992) Standardization of IVGTT to predict IDDM. Diabetes Care 15:13131316

20. Hedstrand H, Boberg J (1975) Statistical analysis of the reproducibility of the intravenous glucose tolerance test and the serum insulin response to this test in the middle-aged men. Scand J Clin Lab Invest 35:331-337

21. Snorgaard O, Hartling SG, Binder C (1990) Proinsulin and Cpeptide at onset and during 12 months cyclosporin treatment of type 1 (insulin-dependent) diabetes mellitus. Diabetologia 33: $36-42$

22. National Diabetes Data Group (1979) Classification and diagnosis of diabetes mellitus and other categories of glucose intolerance. Diabetes 28:1039-1057

23. Vandewalle CL, Coeckelberghs MI, De Leeuw IH et al (1997) Epidemiology, clinical aspects, and biology of IDDM patients under age 40 years. Comparison of data from Antwerp with complete ascertainment with data from Belgium with $40 \%$ ascertainment. The Belgian Diabetes Registry. Diabetes Care 20: $1556-1561$

24. Vandewalle CL, Decraene T, Schuit FC, De Leeuw IH, Pipeleers DG, Gorus FK, the Belgian Diabetes Registry (1993) Insulin autoantibodies and high titre islet cell antibodies are preferentially associated with the HLA DQA $1 * 0301-\mathrm{DQB} *$ 0302 haplotype at clinical onset of Type I (insulin-dependent) diabetes mellitus before age 10 years, but not at onset between age 10 and 40 years. Diabetologia 36:1155-1162

25. Decochez K, Tits J, Coolens J-L et al (2000) High frequency of persisting or increasing islet-specific autoantibody levels after diagnosis of insulin-requiring type 1 diabetes presenting before age 40 years. Diabetes Care 23:838-844

26. Van der Auwera B, Schuit FC, Lyaruu I et al (1995) Genetic susceptibility for insulin-dependent diabetes mellitus in Caucasians revisited: the importance of diabetes registries in disclosing interactions between HLA-DQ- and insulin gene-linked risk. J Clin Endocrinol Metab 80:2567-2573 
27. Kjems LL, Røder ME, Dinesen B, Hartling SG, Jørgensen PN, Binder C (1993) Highly sensitive enzyme immunoassay of proinsulin immunoreactivity with use of two monoclonal antibodies. Clin Chem 39:2146-2150

28. Orban T, Kent SC, Malik P et al (2001) Heterophile antibodies indicate progression of autoimmunity in human type 1 diabetes mellitus before clinical onset. Autoimmunity 34:247-264

29. Heaton DA, Millward BA, Gray P et al (1987) Evidence of beta cell dysfunction which does not lead on to diabetes: a study of identical twins of insulin dependent diabetics. BMJ 294:145146

30. Heaton DA, Millward BA, Gray IP et al (1988) Increased proinsulin levels as an early indicator of B-cell dysfunction in non-diabetic twins of type 1 (insulin-dependent) diabetic patients. Diabetologia 31:182-184

31. Lindgren FA, Hartling SG, Persson BE et al (1993) Proinsulin levels in newborn siblings of type 1 (insulin-dependent) diabetic children and their mothers. Diabetologia 36:560-563

32. Hartling SG, Knip M, Røder ME et al (1997) Longitudinal study of fasting proinsulin in 148 siblings of patients with insulin-dependent diabetes mellitus. Eur J Endocrinol 137:490494

33. Spinas GA, Snorgaard O, Hartling SG, Oberholzer M, Berger W (1992) Elevated proinsulin levels related to islet cell antibodies in first-degree relatives of IDDM patients. Diabetes Care 15:632-637

34. Hartling SG, Røder ME, Dinesen B, Binder C (1996) Proinsulin, C-peptide and insulin in normal subjects during an 8-h hyperglycaemic clamp. Eur J Endocrinol 134:197-200

35. Hostens K, Ling Z, Van Schravendijk C, Pipeleers DG (1999) Prolonged exposure of human beta cells to high glucose increases their release of proinsulin during acute stimulation with glucose or arginine. J Clin Endocrinol Metab 84:1386-1390

36. Ling Z, Pipeleers DG (1996) Prolonged exposure of human beta; cells to elevated glucose levels results in sustained cellular activation leading to a loss of glucose regulation. J Clin Invest 98:2805-2812
37. Hostens K, Pavlovic D, Zambre Y et al (1999) Exposure of human islets to cytokines can result in disproportionately elevated proinsulin release. J Clin Invest 104:67-72

38. Ling Z, Van de Casteele M, Eizirik DL, Pipeleers DG (2000) Interleukin-1 $\beta$-induced alteration in a $\beta$-cell phenotype can reduce cellular sensitivity to conditions that cause necrosis but not to cytokine-induced apoptosis. Diabetes 49:340-345

39. Fourlanos S, Narendran P, Byrnes GB et al (2004) Insulin resistance is a risk factor for progression to type 1 diabetes. Diabetologia 47:1661-1667

40. Snorgaard O, Kjems LL, Røder ME, Hartling SG, Dinesen B, Binder C (1996) Proinsulin immunoreactivity in recent-onset IDDM: the significance of insulin antibodies and insulin autoantibodies. Diabetes Care 19:146-150

41. Hummel M, Williams AJK, Norcross A et al (2001) Proinsulinspecific autoantibodies are relatively infrequent in young offspring with pre-type 1 diabetes. Diabetes Care 24:1843-1844

42. Yu J, Yu L, Bugawan TL et al (2000) Transient anti-islet autoantibodies: infrequent occurrence and lack of association with "genetic" risk factors. J Clin Endocrinol Metab 85:2421-2428

43. Savola K, Läärä E, Vähäsalo P, Kulmala P, Åkerblom HK, Knip M, the Childhood Diabetes in Finland Study Group (2001) Dynamic pattern of disease-associated autoantibodies in siblings of children with type 1 diabetes: a population based study. Diabetes 50:2625-2632

44. Gorus FK, Vandewalle CL, Dorchy H, Van Crombrugge P, Schuit FC, Pipeleers DG (1994) Influence of age on the associations among insulin autoantibodies, islet cell antibodies, and HLA DQA $1 * 0301-\mathrm{DQB} 1 * 0302$ in siblings of patients with type 1 (insulin-dependent) diabetes mellitus. Belgian Diabetes Registry. J Clin Endocrinol Metab 78:1172-1178

45. Elahi D (1996) In praise of the hyperglycemic clamp. A method for assessment of beta-cell sensitivity and insulin resistance. Diabetes Care 19:278-286 